\title{
Formation of Cell-Sized Single-Layered Liposomes in a Simple System of Phospholipid, Ethanol and Water
}

\author{
Kunihiko Goto and Haruo Sato \\ Department of Oncology, The Research Institute for Tuberculosis \\ and Cancer, Tohoku University, Sendai 980
}

\begin{abstract}
Goto, K. and SATo, H. Formation of Cell-Sized Single-Layered Liposomes in a Simple System of Phospholipid, Ethanol and Water. Tohoku J. exp. Med., 1980, 131 (4), 399-407 — A mixture of an ethanolic solution of phospholipid and water was sonicated, kept at $50^{\circ} \mathrm{C}$ for $30 \mathrm{~min}$, and then observed by a phasecontrast microscope. A large number of cell-sized, single-layered liposomes thus obtained were different in shape and thickness from the liposomes prepared by conventional methods. Fixation with $\mathrm{La}\left(\mathrm{NO}_{3}\right)_{3}$ and $\mathrm{KMnO}_{4}$ stabilized the liposomes. As a result they remained unchanged in the organic solvents used for dehydration and embedding. Ultrathin sections of the liposomes could, therefore, be observed with an electron microscope. The nature of these liposomes was discussed in relation to the structure and function of the cell membrane. - ethanol; lanthanum nitrate; semipermeability; cell-sized bilayer; liposome
\end{abstract}

The in vitro formation of closed membranes which are similar to the cell membranes is thought to be of considerable value for understanding the relation between the structure and function exhibited by biological membranes. Previously, closed membranes have been prepared by the following two kinds of method. The first is a method by which closed membranes large enough for microscopic observations can be produced. For example, Chang (1964) developed a method for containing the erythrocyte hemolysates into semipermeable closed membranes, i.e. nylon microcapsules of 1 to $100 \mu \mathrm{m}$ in diameter. The second method is one whereby small closed membranes, liposomes, which are observable with an electron microscope, can be produced. The liposomes have been made by the following procedures: i) by agitating mixtures of lipids and salt solutions with a mixer (0.1$1.0 \mu \mathrm{m}$, multi-layered liposomes) (Bangham et al. 1965); ii) by sonicating the mixtures mentioned above (20-50 nm, single-layered liposomes) (Huang 1969); iii) by injecting an ethanolic solution of phospholipid into a salt solution (about 30 $\mathrm{nm}$, single-layered liposomes) (Batzri and Korn 1973) or by using petroleum ether instead of ethanol (Papahadjopoulos and Watkins 1967); and iv) by dialyzing a solution of phospholipid in a detergent, sodium deoxycholate, against saline solution (less than $0.3 \mu \mathrm{m}$, mainly multi-layered liposomes) (Slack et al. 1973). Recently, two single-layered liposomes of an intermediate size-range (about 0.2

Received for publication, July 24, 1979. 
$\mu \mathrm{m}$ ) were reported (Papahadjopoulos et al. 1975; Deamer and Bangham 1976). They can encapsulate a relatively large percentage of the total aqueous space, but, they are of submicroscopic size, making it difficult to investigate directly for permeability and other properties. Of the closed membranes thus prepared, the larger ones were large enough to be observable by a phase contrast microscope, but they were too thick to be functional. On the other hand, the smaller ones, liposomes, exhibited the property of permeability to electrolytes, a property considered as one of the basic properties of biological membranes, but had a disadvantage of being observable only under the electron microscope. Relatively large, single-layered, closed membranes without the disadvantages described above have thus far not been prepared.

By the application of a new method using phospholipid, ethanol and salt solution, it has become possible to prepare large numbers of cell-sized, single-layered liposomes, which are different from the liposomes obtained by conventional methods. Fixation with $\mathrm{La}\left(\mathrm{NO}_{3}\right)_{3}$ and $\mathrm{KMnO}_{4}$ makes it possible to visualize the cell-sized, single-layered liposomes under the electron microscope.

\section{Materials and Methods}

The lecithin used in this work was prepared from fresh egg yolks according to the method of Faure (1950) and was further purified through a column of silicic acid. The water used was distilled twice in an all-glass apparatus after treatment with ion exchange resin. The salt solution was $0.16 \mathrm{M} \mathrm{KCl}$ adjusted with $1 / 10$ volume of veronal buffer to $\mathrm{pH}$ 7.35. Cholesterol, ethanol, methanol, propanol, glycerol, dimethyl sulfoxide, and sodium deoxycholate were obtained from Junsei Chemical Co., Ltd.

Preparation of cell-sized single-layered liposomes

Varying proportions of a $0.16 \mathrm{M} \mathrm{KCl}$ solution $(0-4 \mathrm{ml})$, the salt solution described above, and the ethanolic solution $(0-4 \mathrm{ml})$ of lecithin $(1.19 \mathrm{mM})$ or lecithin-cholesterol $(1.19$ $\mathrm{mM}$ each) were mixed in a test tube to give a total volume of $4 \mathrm{ml}$ and sonicated for 15 sec without cooling at power level 4 with a Branson sonifier Model W-185. The tube was sealed with alminium foil covered with parafilm and left at $50^{\circ} \mathrm{C}$ for $30 \mathrm{~min}$. The content of each tube was examined for the opacity, fluidity and the presence of crystals. The tube was then opened and about $0.1 \mathrm{ml}$ of the mixture was placed on a clean dish (Petri type, $5 \mathrm{~cm}$ in diameter) and examined under a phase-contrast microscope.

\section{Test of permeability}

The permeability of the large liposomes was examined under the phase-contrast microscope. $0.1 \mathrm{ml}$ of the liposome solution was placed on a dish, and then various electrolyte and nonelectrolyte solutions were dropped onto the sample. $\mathrm{KCl}, \mathrm{NaCl}, \mathrm{Na}_{2} \mathrm{SO}_{4}, \mathrm{Na}_{2} \mathrm{HPO}_{4}$, urea, and sucrose were tested.

Liposomes obtained by conventional methods (Bangham et al. 1965; Papahadjopoulos and Watkins 1967) were used as controls, and their permeability was examined under the same conditions as in the case of the cell-sized single-layered liposomes.

\section{Electron microscopy}

Liposome solution $(0.1 \mathrm{ml})$ in a tube was diluted with $0.16 \mathrm{M} \mathrm{KCl}$ solution $(\mathrm{pH}$ 7.35) to give a final ethanol concentration of $0.8 \%$. Half $\mathrm{ml} \mathrm{of} 1 \% \mathrm{La}\left(\mathrm{NO}_{3}\right)_{3}$ solution, followed by $0.5 \mathrm{ml}$ of $1 \% \mathrm{KMnO}_{4}$ solution (Henn et al. 1967) prepared immediately after filtrating aggregates of $\mathrm{KMnO}_{4}$, was added into the tube. After thorough mixing, the mixture was centrifuged at $3,000 \mathrm{rpm}$ for $5 \mathrm{~min}$. The resulting pellet was washed with 
distilled water three times by centrifugation. The pellet was dehydrated in a series of alcohol and propylene oxide, and embedded in Epon resin. Thin sections cut on a PorterBlum ultramicrotome were mounted on collodion-grids. Without post-staining, all specimens were viewed under a Hitachi 11-B electron microscope.

\section{Results}

\section{Formation of cell-sized, bilayer liposomes}

A mixture of ethanol, water, and lecithin or lecithin-cholesterol was sonicated and observed under a phase-contrast microscope. Large numbers of large bilayer liposomes appeared in the mixture (Figs. 1, 2). The liposomes prepared in a mixture of lecithin, ethanol and water were smooth rod-shaped measuring between 1 and $10 \mu \mathrm{m}$ in length (average size: about $5 \mu \mathrm{m}$ ) (Fig. 1). The liposomes prepared in a mixture of lecithin-cholesterol, ethanol and water were spherical, measuring

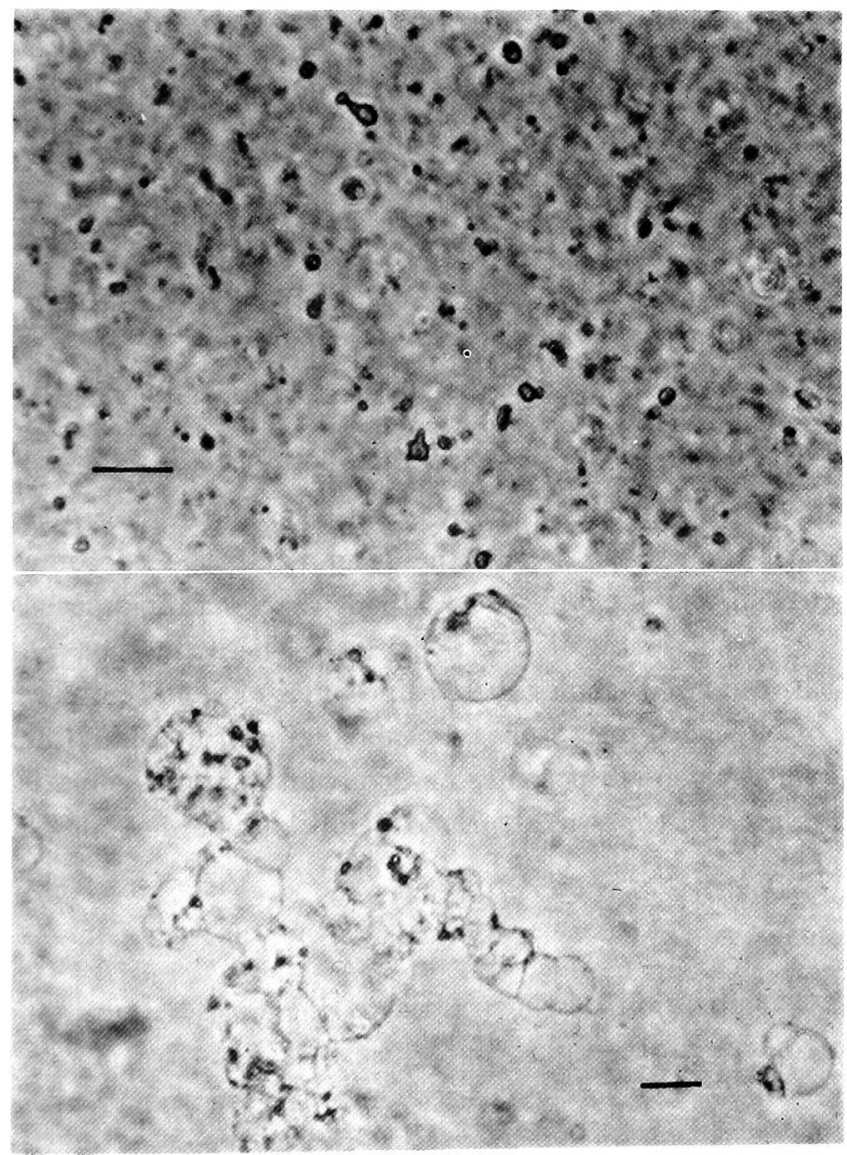

Fig. 1 (upper). The liposomes prepared in the system of lecithin, ethanol, and isotonic veronal buffered $\mathrm{KCl}$ solution. Scale bar $10 \mu \mathrm{m}$.

Fig. 2 (lower). The liposomes prepared in the system of lecithin-cholesterol, ethanol, and isotonic veronal buffered $\mathrm{KCl}$ solution. Scale bar $10 \mu \mathrm{m}$. 
between 1 and $100 \mu \mathrm{m}$ in diameter (average size: about $20 \mu \mathrm{m}$ ) (Fig. 2). Microscopic examinations demonstrated that these liposomes were much thinner in membrane thickness than those formed by the conventional methods. As shown in Fig. 5, the liposomes were formed in a limited range of ethanol concentrations, there appeared a translucent flocculation, which was characteristic of large bilayer liposome formation. At concentrations of 47 to $53 \%(\mathrm{v} / \mathrm{v})$, large amounts of irregular precipitates appeared (Fig. 6), and at lower ethanolic concentrations of about $15 \%$, a small amount of angular precipitates, such as described by Tinker and Saunders (1968), was observed.

Though large and thin, the liposomes were comparatively stable; the liposomes prepared at $35-41 \%$ of ethanol and left at room temperature retained their shapes for more than one month. When the liposome solutions were diluted (to a final ethanol concentration $<0.01 \%$ ) with $0.16 \mathrm{M} \mathrm{NaCl}$ solution, the liposomes remained intact for more than one week.

The liposomes formed by use of other organic solvents (methanol, propanol, glycerol, dimethyl sulfoxide), or sodium cholate and sodium deoxycholate were virtually identical with those obtained by use of ethanol.

\section{Permeability test of cell-sized, single-layered liposomes}

Because the liposomes were large, their permeability could be directly examined by phase-contrast microscopy. Hypertonic solution caused their shrinkage, whereas hypotonic solution caused slight swelling or rupture. With $\mathrm{K}^{+}$and $\mathrm{Na}^{+}$ions, shrinking (Fig. 3) was detected at concentrations of $0.32 \mathrm{M}$, but swelling and rutpure (Fig. 4) were not detected until dilution to $0.02 \mathrm{M}$. With small water-soluble molecules, such as urea, shrinking was not detected at concentrations below $2 \mathrm{M}$. Large hydrated ions such as $\mathrm{SO}_{4}^{--}$and $\mathrm{HPO}_{4}^{--}$caused shrinking at concentration of about $0.25 \mathrm{M}$. On the other hand, the liposomes prepared by conventional methods (Bangham et al. 1965; Papahadjopoulos and Watkins 1967) exhibited no such permeability behavior. These findings indicate that the membranes of the cell-sized single-layered liposomes exhibit semipermeability very similar to that of biological membranes. Since the most notable difference between these cell-sized single-layered liposomes and conventional liposomes is the thickness of their membranes, it seems likely that membrane permeability depends upon membrane thickness.

\section{Electron microscopy}

The direct visualization of the cell-sized single-layered liposomes under the electron microscope was accomplished by use of a new fixation technique.

Of a variety of fixation methods tried, only the treatment with $\mathrm{KMnO}_{4}$ solution after $\mathrm{La}\left(\mathrm{NO}_{3}\right)_{3}$ solution proved to stabilize the liposomes, making them tolerant to the organic solvents used in dehydration and embedding. The liposomes were so large that it was possible to be examined by phase-contrast microscopy, thus allowing for observation during the process of dehydration and embedding. 


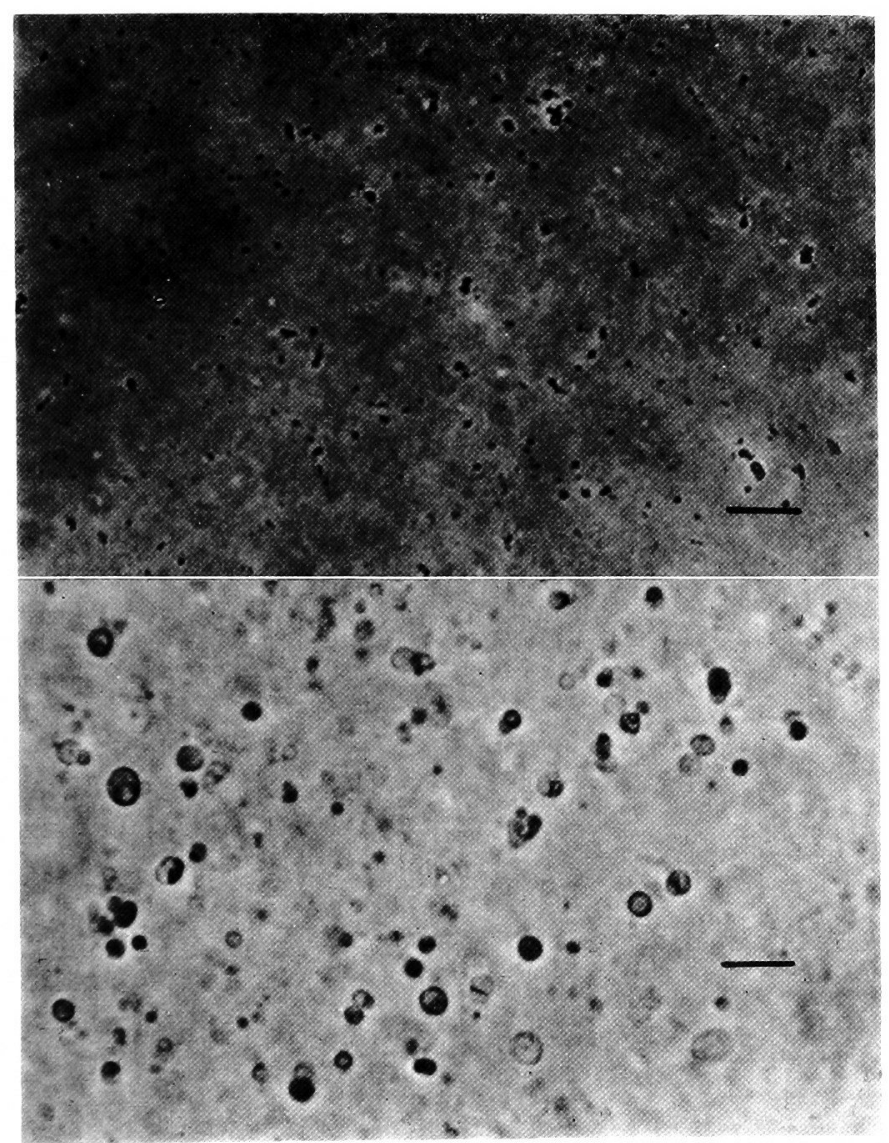

Fig. 3 (upper). The liposomes shrinked shortly after immersion in $0.4 \mathrm{M} \mathrm{NaCl}$. Scale bar $10 \mu \mathrm{m}$.

Fig. 4 (lower). The liposomes swollen in $0.01 \mathrm{M} \mathrm{KCl}$. Scale bar $10 \mu \mathrm{m}$.

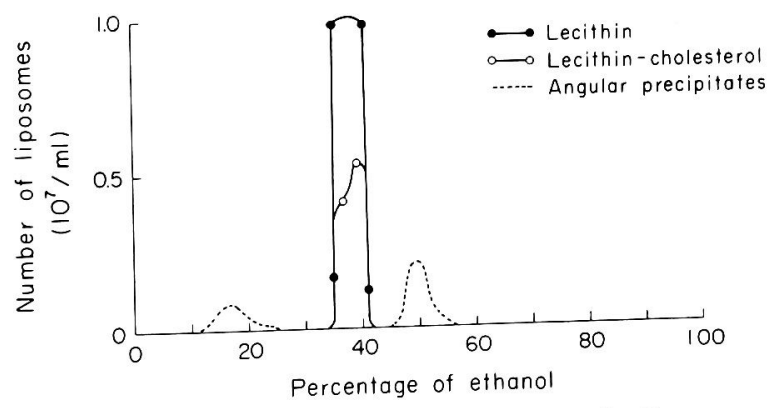

Fig. 5. The concentration of ethanol in preparation of the liposomes. Only the liposomes, the diameter of which exceeded $3 \mu \mathrm{m}$, were counted. 


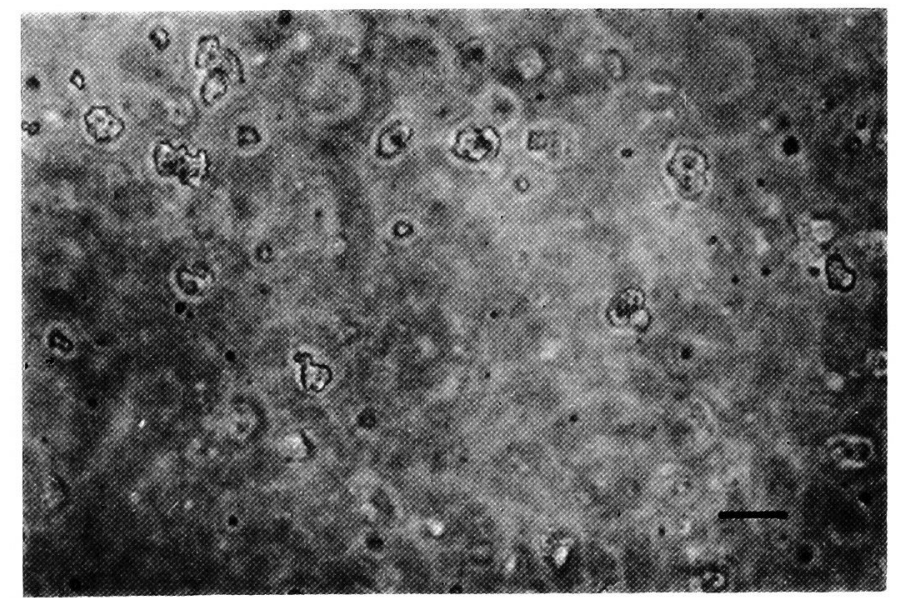

Fig. 6. The irregular precipitates appeared at ethanol concentrations of 47 to $53 \%$. Scale bar $10 \mu \mathrm{m}$.

A combination of two single-layered liposomes is shown in Fig. 7 at a low magnification. Fig. 8 shows that a trilamellar profile (unit membrane structure) in part of the membrane at a high magnification.

They were similar in appearance to the lamellar structures found in hydrated lecithin fixed in $\mathrm{KMnO}_{4}$ (Revel et al. 1958) and also similar to the electron micrographs of phospholipid micelles (Robertson 1960).

\section{Discussion}

In the present experiments an ethanolic solution of lecithin and water was sonicated and kept at room temperature. A large number of cell-sized singlelayered liposomes were thus prepared which could be distinguished from the liposomes obtained by conventional methods. Since changes occur in the shape of liposomes prepared by conventional methods when they are treated with organic solvents for dehydration and embedding (Slack et al. 1973), electron micrographs of the liposomes have been taken on negatively stained specimens. In our experiments the liposomes were treated with lantanium nitrate and fixed in potassium permanganate. The samples thus prepared could be dehydrated with alcohol, and embedded in epoxy resin.

Of the closed membranes so far produced in vitro, only large ones have been observable with the phase contrast microscope, but since they had no lipid, which is a main component of the cell membrane, their significance is unclear. The small ones, liposomes, on the other hand, are made of lipids, the membranes thus prepared exhibit permeability behavior characteristic of the biological membrane, retaining the fundamental functions of the membrane. However, they are so small that they are visible only under the electron microscope. In contrast, the cell-sized single-layered liposomes in this study are thin and exhibit semiper- 


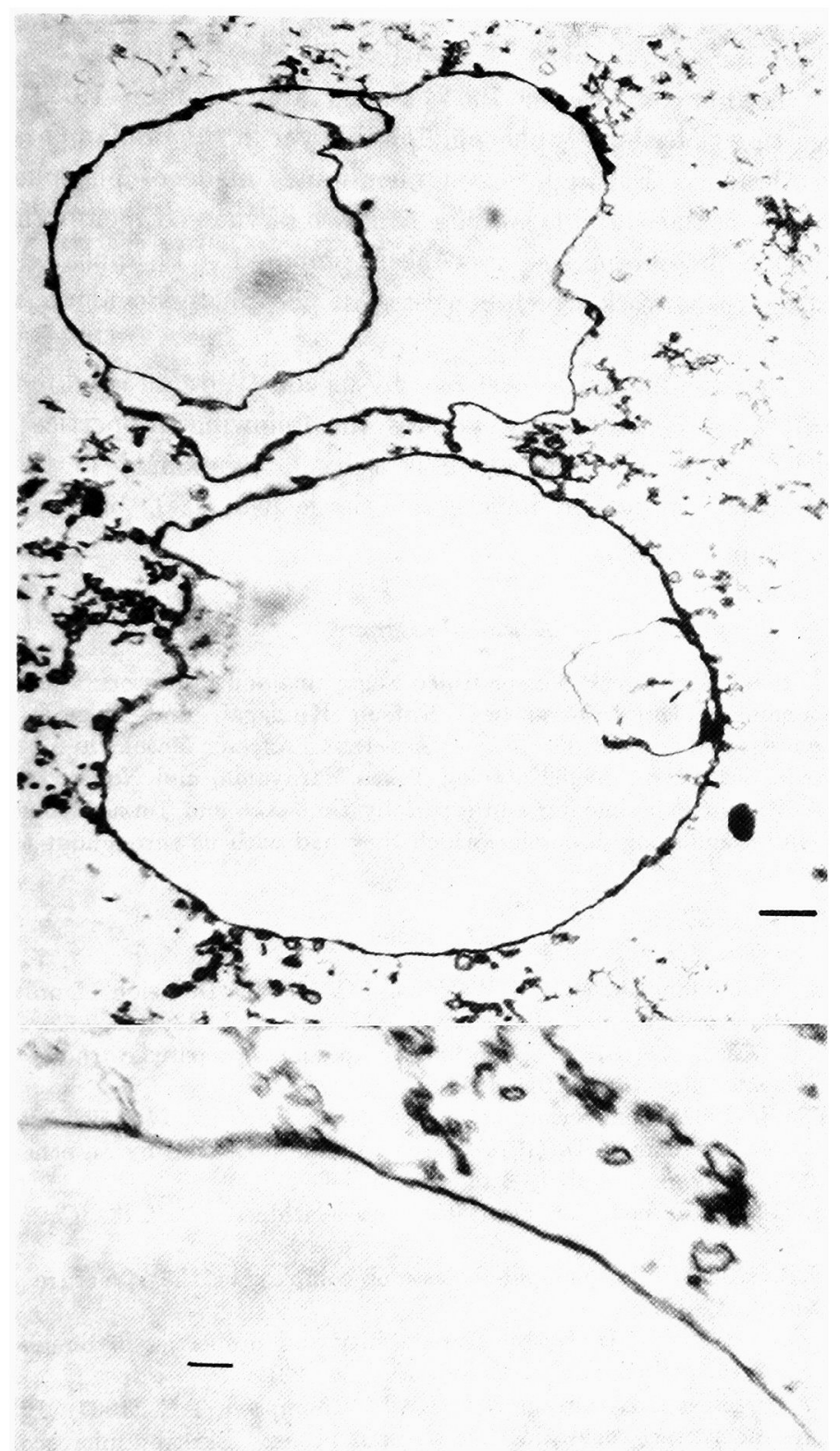

Fig. 7 (upper). The cell-sized single-layered liposomes prepared in the mixture of lecithin, ethanol, and isotonic veronal buffered $\mathrm{KCl}$ solution. Scale bar $5000 \AA$.

Fig. 8 (lower). The membrane of a liposome exhibiting a trilamellar profile in part of the membrane. Scale bar $500 \AA$.

meability very similar to that of the biological membrane. Moreovoer, they are large enough to be visible with a phase contrast microscope. It is of interest that the addition of cholesterol to the liposomes changed their shape from rod form to 
spherical, as shown in Figs. 1 and 2. It is probably due to that cholesterol may stabilize the liposome membranes as described by Finean (1953).

Theories (Haydon and Taylor 1963; Singer and Nicolson 1972) have been presented suggesting that there is phospholipid bilayer in the fundamental structure of the cell membrane. Although closed membranes made of phospholipid alone and having thickness and stability similar to those of the cell membrane were not yet prepared, such membrane has now been prepared. It appeared that the liposomes in the present work which consisted of phospholipids alone were large, thin, and quite stable.

We believe that the liposomes prepared by us constitute an ideal model for the biological membranes because they possess the following properties: (i) These liposomes consist of phospholipid which is a basic component of the biological membrane. (ii) They, moreover, have stable, large (cell-size), bilayer membranes (iii) which are semipermeable.

\section{Acknowledgment}

We wish to thank Assistant Professor Hideo Nagayama and Professors Shuichi Kimura, Toshi Yuki Yamamoto, Taiju Matsuzawa, Katsuo Kumagai, and Shigeru Tsuiki for their encouragement and fruitful discussions; Assistant Professor Masakichi Motomiya and Drs. Fumio Ariji, Seiei Aizu, Seiki Kataoka, Takeo Maruyama, and Nobuaki Tamahashi, who helped us with our experiments; and especially Ikuo Abe and Tetsuo Kimura for the constant help and stimulating discussion which they had with us throughout the work.

\section{References}

1) Bangham, A.D., Standish, M.M. \& Watkins, J.C. (1965) Diffusion of univalent ions across the lamellae of swollen phospholipids. J. mol. Biol., 13, 238-252.

2) Batzri, S. \& Korn, E. (1973) Single bilayer liposomes prepared without sonication. Biochim. biophys. Acta, 298, 1015-1019.

3) Chang, T.M.S. (1964) Semipermeable microcapsules. Science, 146, 524-525.

4) Deamer, D. \& Bangham, A.D. (1976) Large volume liposomes by an ether vaporization method. Biochim. biophys. Acta, 443, 629-634.

5) Faure, M. (1950) Methode de purification des lécithines. Bull. Sté. Chim. Biol., 32, $503-512$.

6) Finean, J.B. (1953) Phospholipid-cholesterol complex in the structure of myelin. Experientia, 9, 17-19.

7) Haydon, D.A. \& Taylor, J. (1963) The stability and properties of bimolecular lipid leaflets in aqueous solutions. $J$. theoret. Biol., 4, 281.

8) Henn, F.A., Decker, G.L., Greenawalt, J.W. \& Thompson, T.E. (1967) Properties of lipid bilayer membranes separating two aqueous phase: Electron microscope studies. J. mol. Biol., 24, 51-58.

9) Huang, C.H. (1969) Studies on phosphatidyl choline vesicles. Formation and physical characteristics. Biochemistry, 8, 344-351.

10) Papahadjopoulos, D. \& Watkins, J.C. (1967) Phospholipid model membranes II. Permeability properties of hydrated liquid crystals. Biochim. biophys. Acta, 135, 639-652.

11) Papahadjopoulos, D., Vail, W.J, Jacobson, K. \& Poste, G. (1975) Cochleate lipid cylinders: Formation by fusion of unilamellar lipid vesicles. Biochim. biophys. Acta, 394, 483-491.

12) Revel, J.P., Ito, S. \& Fawcett, D.W. (1958) Electron micrographs of myelin figures 
of phospholipid simulating intracellular membranes. J. biophys. biochem. Cytol., 4, 495.

13) Robertson, J.D. (1960) The molecular structure and contact relationships of cell membranes. Prog. Biophys., 10, 343-418.

14) Singer, S.J. \& Nicolson, G.L. (1972) The fluid mosaic model of the structure of cell membranes. Science, 175, 720-731.

15) Slack, J.R., Anderton, B.H. \& Day, W.A. (1973) A new method for making phospholipid vesicles and the partial reconstitution of the $\left(\mathrm{Na}^{+}, \mathrm{K}^{+}\right)$-activated ATPase. Biochim. biophys. Acta, 323, 547-559.

16) Tinker, D.O. \& Saunders, L. (1968) Studies of isotropic phosphatidylcholine-npropanol-water systems. Chem. Phys. Lipids, 3, 316-329. 